Gut, 1963, 4, 360

\title{
Peptic ulcer in south-west Scotland
}

\author{
A. $\operatorname{LITTON}^{1}$ AND W. R. MURDOCH
}

From Dumfries and Galloway Royal Infirmary, Dumfries, Scotland

EDITORIAL SYNOPSIS A survey is made of the incidence of peptic ulcer in a predominantly rural population in south-west Scotland.

The prevalence of peptic ulcer in modern society, with its resultant chronic ill health and economic hardship, justifies continued interest in its incidence and aetiology. Recent analysis of the aetiological factors has shown a wide variety of views, but it would appear that there is a difference in the occurrence of peptic ulcer in rural and other communities. Although a number of reports (e.g., Doll and Jones, 1951; Pulvertaft, 1959) deal with urban surveys, there are few studies of the prevalence of peptic ulcer in rural areas or in the community as a whole.

${ }^{1}$ Present address: Southern General Hospital, Glasgow, S.W.1.

${ }^{2}$ Present address: Victoria Infirmary, Glasgow.
Methods of estimating frequency have serious limitations. General practitioner, hospital, and necropsy surveys, for example, deal with selected groups. It has been suggested that if accuracy of diagnosis could be established population surveys, although expensive and time consuming, would provide the best method of assessing the incidence of peptic ulcer (Lancet, 1960).

Our survey concerns peptic ulcers which occurred between 1957 and 1959 in the population of the predominantly rural area consisting of the counties of Dumfries, Kirkcudbright, and Wigtown. The only large town, containing the general hospital for

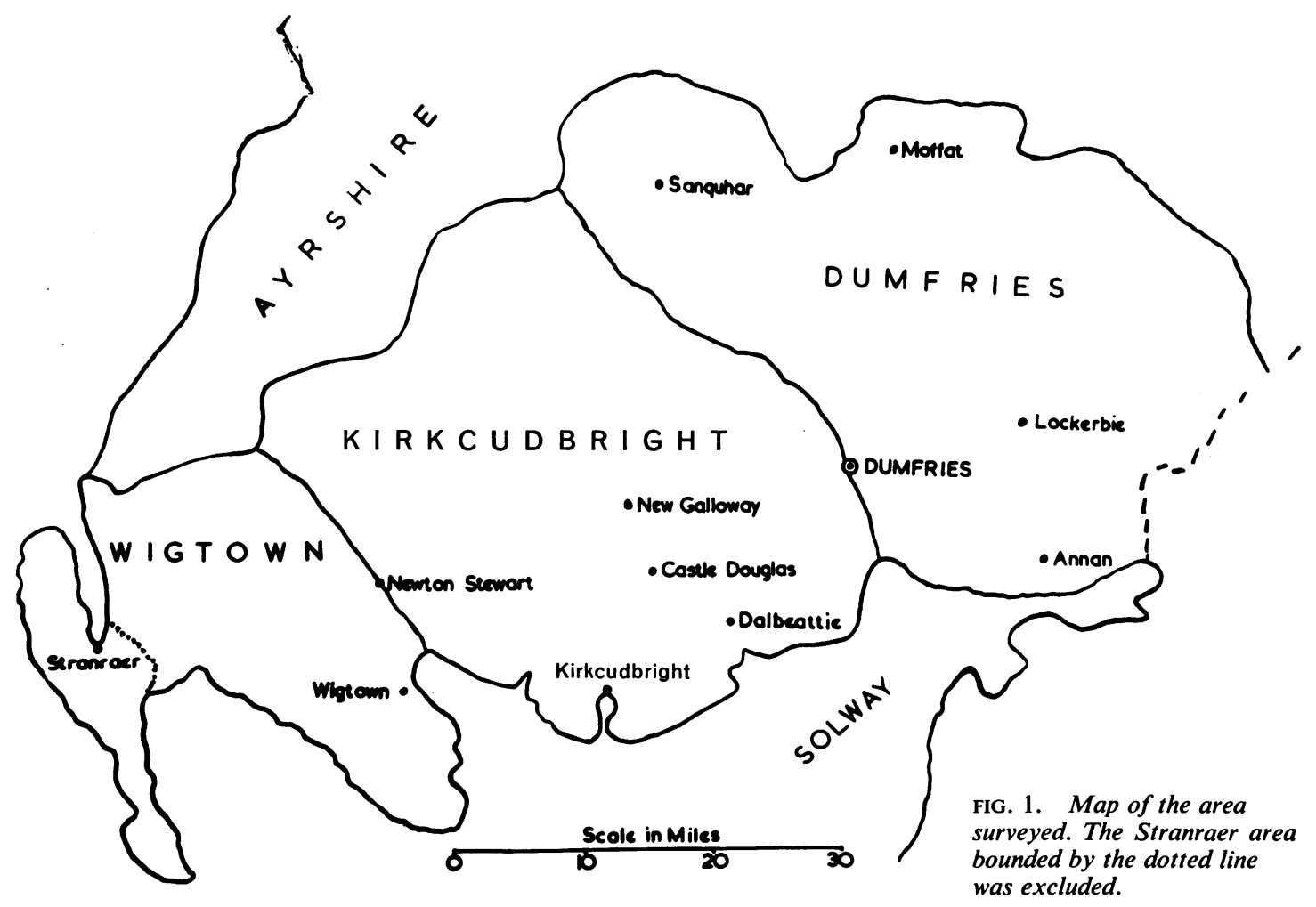


the area, is Dumfries, with a population of 26,322 (Fig. 1). Although a small number of patients on the borders of the counties may be referred to hospitals in Ayrshire and Carlisle, the vast majority are seen either at the hospital or at its peripheral clinics. The Stranraer area has a small hospital of its own and is excluded from the survey. The population of Dumfries and the rural area is shown in Table I. As the radiological services in the area are open to general practitioners, in addition to our hospital series we have been able to obtain details of patients with radiologically proven peptic ulcer treated by their own doctors.

TABLE I

POPULATION SURVEYED

Sex Total Population

Population

Aged

15 Years

and Over

\begin{tabular}{lllr}
\hline Urban (Dumfries) & Male & 12,181 & 9,125 \\
& Female & 14,141 & 11,160 \\
& Total & 26,322 & 20,285
\end{tabular}

Rural (Dumfries and

$\begin{array}{llrr}\text { Galloway less Stranraer area) } & \text { Male } & 53,954 & 39,745 \\ & \text { Female } & 55,729 & 42,595\end{array}$ $\begin{array}{lrr}\text { Female } & 55,729 & 42,595 \\ \text { Total } & 109,683 & 82,340\end{array}$

Grand total Male $\quad 66,135 \quad 48,870$ \begin{tabular}{lrr} 
Female & 69,870 & 53,755 \\
\hline
\end{tabular}

The diagnosis of peptic ulcer was confirmed radiologically in the majority of cases, the remainder being composed of acute perforations or peptic ulcers diagnosed at laparotomy. Cases of alimentary bleeding suggestive of peptic ulcer were excluded unless there was positive radiological or operative evidence of ulceration.

\section{PEPTIC ULCER}

In the three-year survey (1957-59), there was a total of 944 cases of peptic ulcer consisting of 810 patients with duodenal ulcer, 106 with gastric ulcer, and 28

\section{TABLE II}

PATIENTS WITH ACUTE SYMPTOMS OF PEPTIC ULCER IN DUMFRIES AND GALLOWAY, 1957-59

\begin{tabular}{lrrr} 
Ulcer & Male & Female & Total \\
\hline Duodenal & 607 & 203 & 810 \\
Gastric & 57 & 49 & 106 \\
Combined gastric and duodenal & 24 & 4 & 28 \\
Total & 688 & 256 & 944
\end{tabular}

cases of combined gastric and duodenal ulcer. The figures are analysed in Table II. In further analyses the combined ulcers are included in both the duodenal and the gastric ulcer totals.

\section{DUODENAL ULCER}

Of the 838 cases of duodenal ulcer, 631 were in males and 207 in females. The overall mean annual incidence of duodenal ulcer per 1,000 males 15 years and over is 5.42 and for females is 1.28 , the male/female ratio being $4 \cdot 22 / 1$.

\section{GASTRIC ULCER}

Of the 134 cases of gastric ulcer, 81 were in males and 53 in females, giving an annual incidence per 1,000 of 0.55 for males and $\mathbf{0 . 3 2}$ for females, the sex ratio being $1 \cdot 7 / 1$. The duodenal ulcer/gastric ulcer ratio in males is $7 \cdot 8 / 1$ and in females is $3 \cdot 9 / 1$.

\section{INCIDENCE IN TOWN AND COUNTRY}

Although Dumfries can hardly be regarded as a highly industrialized centre, yet it seemed worth while to compare it with the surrounding rural area. Thus of 9,125 males, aged 15 years and over in Dumfries, 226 had active duodenal ulcers during the three-year survey, giving an annual incidence per 1,000 of $8 \cdot 26$. In the country group of 39,745 males there were 405 duodenal ulcers, an annual incidence of 3.40. From these figures duodenal ulcer in males was 2.43 times more common in town than in the country. Similarly 72 females in a population of 11,160 over 15 years of age in Dumfries had duodenal ulceration, the annual incidence per 1,000 being $2 \cdot 15$. One hundred and thirty-five women in the rural area with 42,595 women over 15 years of age had duodenal ulcers, giving an annual incidence of 1.06. This gives a ratio of town to country as $2.03 / 1$ in females.

The corresponding figures for gastric ulcer in males were 32 in the town and 49 in the country, giving an annual incidence per 1,000 of 1.17 and 0.41 respectively. Thus gastric ulcers were 2.84 times more common in the town than in the country. In women, over the same three-year period, there were 19 gastric ulcers in the town and 34 in the country, an incidence of 0.57 and 0.27 respectively, giving a town/country ratio of $2 \cdot 12 / 1$.

\section{AGE AND DURATION OF SYMPTOMS}

As peptic ulcer is a chronic disease with episodes of increased activity, the duration of previous symptoms was often difficult to assess accurately. For example, a person with perforation of a peptic ulcer may not immediately admit to previous symptoms because of the urgent nature of his presenting illness, yet on closer questioning confesses to recurrent dyspepsia of several years' duration. For this reason we have 
TABLE III

INCIDENCE OF DUODENAL ULCER PER ANNUM

\begin{tabular}{|c|c|c|c|c|c|c|c|c|c|c|}
\hline \multirow{3}{*}{$\begin{array}{l}\text { Age Groups } \\
\text { (yr.) }\end{array}$} & \multicolumn{5}{|l|}{ Men } & \multicolumn{5}{|c|}{ Women } \\
\hline & \multicolumn{2}{|c|}{ Dumfries } & \multicolumn{2}{|c|}{ Rural } & \multirow[t]{2}{*}{ Total } & \multicolumn{2}{|c|}{ Dumfries } & \multicolumn{2}{|c|}{ Rural } & \multirow[t]{2}{*}{ Total } \\
\hline & No. & Per 1,000 & No. & Per 1,000 & & No. & Per 1,000 & No. & Per 1,000 & \\
\hline$<20$ & 5 & 2.01 & 7 & 0.63 & 12 & 1 & 0.35 & - & - & 1 \\
\hline $20-29$ & 33 & $5 \cdot 78$ & 54 & $2 \cdot 30$ & 87 & 8 & $1 \cdot 24$ & 10 & 0.43 & 18 \\
\hline $30-39$ & 45 & $8 \cdot 22$ & 92 & 4.06 & 137 & 19 & $3 \cdot 21$ & 25 & $1 \cdot 15$ & 44 \\
\hline $40-49$ & 53 & 10.00 & 67 & 3.02 & 120 & 16 & 2.68 & 40 & 1.79 & 56 \\
\hline 50-59 & 60 & 15.45 & 96 & 5.72 & 156 & 17 & $3 \cdot 19$ & 34 & $1 \cdot 72$ & 51 \\
\hline $60-69$ & 22 & 8.71 & 61 & $5 \cdot 57$ & 83 & 7 & 1.74 & 16 & 0.99 & 23 \\
\hline 70 and over & 8 & 2.77 & 28 & 2.82 & 36 & 4 & 1.39 & 10 & 0.73 & 14 \\
\hline Total & 266 & $8 \cdot 26$ & 405 & 3.40 & 631 & 72 & $2 \cdot 15$ & 135 & $1 \cdot 19$ & 207 \\
\hline
\end{tabular}

considered only age at the time of first attendance during the three-year period under review. We have taken into consideration the population at risk in each age group. The results are shown in Table III.

In persons under 20 years of age peptic ulcer is not common, and its prevalence in the group aged 20 to 29 years is lower than in the following decades. Like other authors we have found a maximum

\section{TABLE IV}

DURATION OF SYMPTOMS IN PEPTIC ULCER

\begin{tabular}{|c|c|c|c|c|}
\hline \multirow[t]{2}{*}{ Duration (yr.) } & \multicolumn{2}{|c|}{ Duodenal (\%) } & \multicolumn{2}{|c|}{ Gastric $(\%)$} \\
\hline & Male & Female & Male & Female \\
\hline $\begin{array}{c}<1 \\
1-5 \\
6-10 \\
11-15 \\
16-20 \\
>20\end{array}$ & $\begin{array}{r}18 \cdot 8 \\
25 \cdot 7 \\
24 \cdot 7 \\
11.5 \\
7 \cdot 6 \\
12.0\end{array}$ & $\begin{array}{r}25 \cdot 1 \\
28 \cdot 6 \\
18 \cdot 7 \\
14 \cdot 8 \\
3 \cdot 4 \\
9 \cdot 4\end{array}$ & $\begin{array}{r}38 \cdot 6 \\
19 \cdot 3 \\
12 \cdot 3 \\
14 \cdot 0 \\
5 \cdot 3 \\
10 \cdot 5\end{array}$ & $\begin{array}{r}38 \cdot 8 \\
26 \cdot 5 \\
10 \cdot 2 \\
14 \cdot 2 \\
2.0 \\
8 \cdot 2\end{array}$ \\
\hline
\end{tabular}

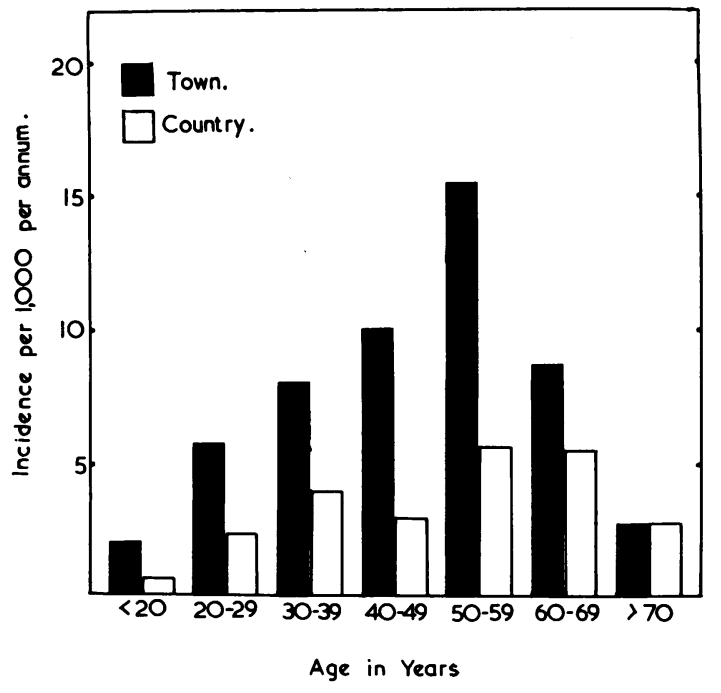

FIG. 2. The incidence of duodenal ulcer in men aged 15 years and over related to town and country. incidence of duodenal ulcer in men in the 50 to 59 age group (Fig. 2). After 60 years of age, the number related to the population at risk declined.

The series of gastric ulcers is small, rendering analysis difficult. In men and women the maximum incidence was in the decade 60 to 69 years, 10 years later than duodenal ulcer.

An attempt was made to assess the duration of symptoms at the time of diagnosis and the results are shown in Table IV. It is interesting to note that in more than a third of the patients with gastric ulcer the duration of symptoms was less than one year. A similar short duration of symptoms is usual in gastric carcinoma.

\section{INCIDENCE AND SOCIAL CLASS}

Previous authors have correlated the incidence of peptic ulcer with social status. Although social status appeared to have little bearing in duodenal ulcer all agreed that there is an increased prevalence of gastric ulcer in the unskilled (Morris and Titmuss, 1944: Doll and Jones, 1951; Pulvertaft, 1959).

The composition of the population in our area according to social class was taken from the 1951 census (Scotland) tables. There does not appear to have been any appreciable difference in the various social class groups from 1951 till the three years under review in 1957 to 1959 . In men, the occupations

TABLE V

PEPTIC ULCER AND SOCIAL CLASS IN MALES ONLY

\begin{tabular}{lcccc}
$\begin{array}{l}\text { Social } \\
\text { Class }\end{array}$ & $\begin{array}{l}\text { Duodenal } \\
\text { Ulcer }\end{array}$ & $\begin{array}{l}\text { Duodenal } \\
\text { Ulcer } \\
\text { Expected }\end{array}$ & $\begin{array}{l}\text { Gastric } \\
\text { Ulcer }\end{array}$ & $\begin{array}{l}\text { Gastric } \\
\text { Ulcer } \\
\text { Expected }\end{array}$ \\
\hline I & 13 & 14 & - & 2 \\
II & 41 & 80 & 11 & 11 \\
III & 125 & 218 & 12 & 30 \\
IV & 136 & 108 & 13 & 14 \\
V & 158 & 52 & 28 & 7 \\
& Total 473 & & Total 64 &
\end{tabular}

For duodenal ulcer $x^{2}=282.07 \quad \mathrm{P}<0.001$

For gastric ulcer $\chi^{2}=85.87 \quad \mathrm{P}<0.001$ 
of 473 patients with duodenal ulcer and 64 with gastric ulcer were recorded and placed in the social class groups as defined by the Registrar General. On the hypothesis that peptic ulcer would be distributed evenly throughout all social groups, we calculated from the population tables the expected number of peptic ulcers in each group. The results are tabulated in Table V.

We found that as with gastric ulcer, duodenal ulcer had a correlation with social class. Statistical analysis confirmed that there was a significantly increased prevalence of duodenal ulcer in unskilled workers. In women there were few records of social class.

\section{OCCUPATION}

In previous studies, attempts were made to assess the incidence of peptic ulcer in various occupations.

Although Dumfries and Galloway is predominantly a rural area, only $26 \%$ of the employed males (15 years and over) were engaged in agricultural occupations (agriculture, forestry, and horticulture). We recorded the occupations of 473 males with duodenal ulcer and 64 males with gastric ulcer and compared agricultural occupations with all others (Table VI). Duodenal ulcer was less common in agricultural workers relative to other occupations. Our findings are in agreement with those of Doll and Jones (1951). In contrast to duodenal ulcer we found no significant variation in the incidence of gastric ulcer in agricultural workers.

TABLE VI

AGRICULTURE AND OTHER OCCUPATIONS OF ULCER PATIENTS

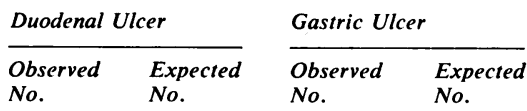

Agricultural occupations All others Total

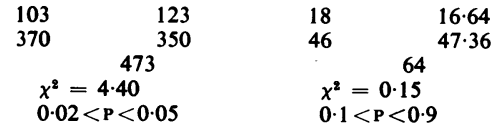

\section{HAEMORRHAGE AND PERFORATION}

Haemorrhage occurred in approximately a quarter of the males with peptic ulcer and perforation of the ulcer occurred in just less than one in 10 . In women peptic ulcer was a more benign condition; slightly fewer than one in five sustained haemorrhage from the ulcer and only $3.5 \%$ perforated. Table VII expresses the figures for haemorrhage, perforation, and other clinical symptoms.

The incidence of haemorrhage from peptic ulcer was compared in town and country (Table VIII).
TABLE VII

DISTRIBUTION OF PEPTIC ULCER BY SYMPTOMS

\begin{tabular}{lcc} 
& Males & Females \\
\hline Haemorrhage & $160(23 \cdot 3 \%)$ & $49(19 \cdot 1 \%)$ \\
Perforation & $62(9 \cdot 0 \%)$ & $9(3.5 \%)$ \\
Other clinical symptoms & $466(67.7 \%)$ & $198(77 \cdot 4 \%)$ \\
Total & 688 & 256
\end{tabular}

TABLE VIII

INCIDENCE OF HAEMATEMESIS IN THREE-YEAR PERIOD 1957-59

\begin{tabular}{|c|c|c|c|c|}
\hline & \multicolumn{2}{|l|}{ Male } & \multicolumn{2}{|l|}{ Female } \\
\hline & Town & Country & Town & Country \\
\hline Duodenal ulcer & 49 & 92 & 13 & 25 \\
\hline Gastric ulcer & 5 & 5 & 4 & 7 \\
\hline Combined ulser & 4 & 5 & 工 & - \\
\hline Total & 58 & 102 & 17 & 32 \\
\hline over) & $(2 \cdot 12)$ & $(0.856)$ & $(0 \cdot 508)$ & $(0 \cdot 25)$ \\
\hline
\end{tabular}

The incidence per 1,000 (aged 15 years and over) for men was 2.12 in town and 0.856 in the rural area and for women was 0.51 and 0.25 respectively. Haemorrhage from ulcer was 2.48 times more common in

TABLE IX

INCIDENCE OF PERFORATION IN THREE-YEAR PERIOD 1957-59

\begin{tabular}{|c|c|c|c|c|}
\hline & \multicolumn{2}{|l|}{ Males } & \multicolumn{2}{|l|}{ Females } \\
\hline & Town & Country & Town & Country \\
\hline \multirow{3}{*}{$\begin{array}{l}\text { Duodenat uker } \\
\text { Gastric uleer } \\
\text { Stomal ulcer }\end{array}$} & 25 & 34 & 4 & 4 \\
\hline & - & - & 1 & - \\
\hline & 2 & 1 & - & - \\
\hline \multirow{2}{*}{$\begin{array}{l}\text { Total } \\
\text { Annual incidence per } \\
1,000 \text { (aged } 15 \mathrm{yr} \text {. and } \\
\text { over) }\end{array}$} & 27 & 35 & 5 & 4 \\
\hline & $(0.986)$ & $(0 \cdot 292)$ & $(0 \cdot 149)$ & $(0.031)$ \\
\hline
\end{tabular}

males living in town compared with males living in the country. The ratio for women was 2.08. A similar comparison was made for perforation (Table IX). This gave a town-to-country ratio of $3 \cdot 37 / 1$ in males and $4 \cdot 77 / 1$ in females.

It has been suggested that easy access to diagnostic facilities leads to a higher apparent prevalence of peptic ulcer in the town. Perhaps owing to the distances involved, the countryman finds it more difficult to consult his own doctor, but haematemesis and perforation being dramatic in their onset compel patients to seek medical help no matter where they stay.

The town-to-country ratio of peptic ulcer and its complications are summarized in Table $\mathrm{X}$. The ratio of haematemesis in men and women closely parallels 
TABLE $X$

TOWN AND COUNTRY RATIOS OF PEPTIC ULCER AND ITS COMPLICATIONS

Town and Country Ratios

\begin{tabular}{lll} 
& Male & Female \\
\hline Duodenal ulcer & $2 \cdot 43: 1$ & $2 \cdot 03: 1$ \\
Gastric ulcer & $2 \cdot 82: 1$ & $2 \cdot 13: 1$ \\
Perforation & $3 \cdot 37: 1$ & $4 \cdot 77: 1$ \\
Haematemesis & $2 \cdot 48: 1$ & $2 \cdot 08: 1$
\end{tabular}

the ratio of both duodenal and gastric ulcer as a whole, suggesting that the increased prevalence of peptic ulcer in the town is real. Although the numbers are small, the higher incidence of perforation in the town might indicate that peptic ulcer was a more active condition in an urban community.

\section{TREATMENT}

It is not our intention to discuss treatment in detail. Most patients were treated along conventional lines with diet and antacids. In $21 \%$ of cases, patients were treated solely by their general practitioners. Of 209 cases of haemorrhage, only 10 patients required emergency surgery for haemorrhage uncontrolled by medical measures. However, elective surgical treatment was carried out in a further 53 patients, who had a history of recurrent haematemesis. The number of deaths directly attributable to haemorrhage was nine $(4.3 \%)$. This low mortality, in association with the low emergency surgery rate, suggests that in our area haemorrhage is a less severe complication of peptic ulcer than in large towns.

\section{PERFORATION}

Simple suture was the standard emergency treatment of perforation. There were five deaths in a total of 71 cases $(7 \%)$. One patient, a married woman aged 52 years, was admitted to hospital in a moribund state, three days after the onset of severe abdominal

TABLE XI

SURGICAL TREATMENT OF PEPTIC ULCER

\begin{tabular}{|c|c|c|c|}
\hline & $\begin{array}{l}\text { No. of } \\
\text { Male }\end{array}$ & $\begin{array}{l}\text { No. of } \\
\text { Female }\end{array}$ & Total \\
\hline $\begin{array}{l}\text { Duodenal ulcer } \\
\text { Gastric ulcer } \\
\text { Combined ulcers }\end{array}$ & $\begin{array}{c}172(28.33 \%) \\
32(56.13 \%) \\
15(62.5 \%)\end{array}$ & $\begin{array}{l}41(20 \cdot 19 \%) \\
12(24 \cdot 5 \%) \\
2(50 \%)\end{array}$ & $\begin{array}{c}213(26.29 \%) \\
44(41.5 \%) \\
17(60.7 \%)\end{array}$ \\
\hline Total & $219(31.8 \%)$ & $55(21.5 \%)$ & $274(29 \%)$ \\
\hline
\end{tabular}

pain. At necropsy an unsuspected perforated duodenal ulcer was found. There were four post-operative deaths, all in males over 65 years of age. The details of surgical treatment for peptic ulcer as a whole are shown in Table XI. Three out of every 10 men and two out of every 10 women with acute symptoms had surgical treatment.

\section{DISCUSSION}

The frequency of peptic ulcer and the pattern of the disease has been reported from many countries. Dogra $(1940,1941)$ showed a higher incidence in southern India than in northern India, and Konstam (1954) reported a similar unequal distribution in Nigeria. Alsted (1953) reviewed the pattern in Denmark and found a higher incidence in towns than in rural districts. In Britain several reports have been published but many more are required before a complete picture of peptic ulcer throughout the country can be obtained. Morris and Titmuss (1944) reported a lower mortality from ulcer in rural than in urban communities. Pulvertaft (1959) found a higher frequency in York than in the adjoining rural area. In our series, where $80 \%$ of the population is rural, the incidence of peptic ulcer in the burgh of Dumfries was approximately twice as great as in the surrounding country.

In a large number of cases, ulcer symptoms had been present for years before the patient sought medical aid. Difficulties in defining the onset of symptoms or of including patients with proven but inactive ulcers make comparison of various series difficult. Comparison of perforation figures, however, is more precise and it is interesting to compare our area with Glasgow (Jamieson, 1955) and York (Pulvertaft, 1959) (Table XII). The incidence of

TABLE XII

COMPARISON OF INCIDENCE OF PERFORATION IN PEPTIC ULCER

\begin{tabular}{lllc} 
Area & Author & \multicolumn{2}{c}{$\begin{array}{l}\text { Incidence } \\
\text { Population }\end{array}$} \\
& & Male & Female \\
\hline Glasgow (1952-53) & Jamieson (1955) & 32.6 & $3 \cdot 2$ \\
York (1952-53) & Pulvertaft (1959) & 26.6 & $2 \cdot 8$ \\
Dumfries (1957-59) & Present series & 15.2 & $2 \cdot 2$
\end{tabular}

perforation in Dumfries and Galloway is lower than in York and considerably lower than in Glasgow. In a report (1960) from Aberdeen, Weir found that the annual incidence of duodenal ulcer perforations (1946-56) in males aged 15 years and over was 0.88 per 1,000 in Aberdeen city, 0.75 in the north-east small boroughs, and 0.62 in landward areas. The rates in south-west Scotland in 1957-59 were 0.91 for the burgh of Dumfries and 0.28 for rural areas. The incidence of duodenal ulcer perforations in males in the burgh of Dumfries is very similar to Aberdeen. The perforation rate for women 
appears to be reasonably comparable in the various series. Illingworth, Scott, and Jamieson (1944) reported a much higher perforation rate in men than in women. The sex ratio in 1944 in the Glasgow area was $19 / 1$. Jamieson in 1955 reported that the ratio had fallen to 12/1. In our series (1957-59) in Dumfries and south-west Scotland the sex ratio was $7 / 1$. The diminishing sex ratio may indicate that perforation in women is becoming more common.

The mortality from perforation in the Glasgow series had fallen over 30 years from $25 \%$ to about $8 \%$ (Jamieson, 1955). The mortality rate in our series (1957-59) was 7\%. Jones and Doll (1953) reported a mortality rate in the south of England of $7.9 \%$. Weir (1960) found the mortality in northeast Scotland to be $4.4 \%$ in 1958 . All authors agree that there is a very appreciable mortality in perforation in the elderly. In our series the mortality for males over 60 years was $30 \%$.

The influence of social class on the occurrence of gastric ulcer was demonstrated by Morris and Titmuss (1944) and by Doll and Jones (1951) but both these authors were unable to show a similar relationship for duodenal ulcer. Pulvertaft (1959) in the York survey showed that both types of ulcer were influenced by social class and our findings in south-west Scotland also revealed an increase of both duodenal and gastric ulcers in unskilled persons. In the Aberdeen report (Weir, 1960) the perforation rate was also increased in the lower social classes. Our results and those of Doll and Jones (1951) indicate a decreased liability to duodenal ulcer in agricultural workers, which is contrary to the findings of Pulvertaft (1959) in York. Gastric ulcer, however, was just as common in agricultural workers as in the rest of the population.

Combined gastric and duodenal ulcers constitute only a small percentage of the total numbers of peptic ulcers. Mangold (1958) in a series of peptic ulcers from the Central Middlesex Hospital reported $2.7 \%$ of combined ulcers compared with $2.96 \%$ in our series. It is noted that the percentage of combined uicers requiring surgical treatment is higher than for either duodenal or gastric ulcers separately. Mangold's combined ulcer series had an operation rate of $52 \%$, whereas in our series $60.7 \%$ had surgical treatment. While careful necropsy surveys, for example that of Watkinson (1960), can indicate precisely the presence of active peptic ulceration, or the scarring of healed ulcers, these hospital reports are difficult to correlate with clinical estimates of the morbidity caused by peptic ulceration in the population as a whole.

On the other hand, surveys by general practitioners, though limited in their numbers and perhaps by the composition and situation of the practice, help to delineate the problem of peptic ulcer in the community. Finer and Fry (1955) in a London practice showed that haemorrhage occurred in $18 \%$ and perforation in $10 \%$ of those with peptic ulcer, while $25 \%$ of all cases required surgical treatment. Lipetz (1955) reported that in a general practice in Edinburgh $16.4 \%$ had haemorrhage and $19.2 \%$ suffered perforation. In Pulvertaft's (1959) hospital series $15.8 \%$ males and $16.5 \%$ females had haemorrhage and $13.7 \%$ males and $7.8 \%$ females had perforation. In our series of hospital and general practitioner cases, we found that $23.3 \%$ of males and $19.1 \%$ of females sustained a haemorrhage and $9 \%$ males and $3.5 \%$ females had a perforation. The overall operation rate was $29 \%$.

One cannot readily obtain an overall picture of the prevalence of the disease in areas where patients may be referred to one of several hospitals or to specialized units. In this respect we have been fortunate in studying a compact community with a single general hospital.

Although peptic ulcer is a common disease it is difficult to account for its increase in the town of Dumfries compared with the surrounding countryside. There are several factories and workshops in Dumfries but no significant atmospheric pollution. As far as we could observe there was no difference in dietary habits. Perhaps urban employment attracts the ambitious, and by its competitive nature leads to increased stress in the town. It is possible that ulcer patients in the country, finding difficulty in coping with heavy agricultural work, seek lighter urban employment.

Today in spite of our better understanding of gastric function, and the pharmacological action of antacids and other drugs, man problems remain in the management of peptic ulcer patients. Perhaps further studies similar to our own will elucidate important aetiological factors in this common modern disease.

\section{SUMMARY}

A survey of the incidence of pəptic ulcer in rural south-west Scotland was made in the three-year period 1957-59. Nine hundred and forty-four patients with acute symptoms of peptic ulcer were studied. Diagnosis in all cases was confirmed radiologically or by laparotomy. The survey included cases both in hospital and in general practice, $21 \%$ cases being treated solely by family doctors. In both men and women gastric and duodenal ulcers were twice as common in town as in the country.

In the area surveyed the incidence of perforation was less than in York, north-east Scotland, and Glasgow. 
Both gastric and duodenal ulcers were related to social class, being more common in the unskilled groups. Agricultural workers were less susceptible to duodenal ulceration although the incidence of gastric ulcer was not significantly different from that of the general population. In peptic ulcer patients, haemorrhage occurred in approximately one in four of the males and one in five of the females and perforation in one in 10 of the males and one in 28 of the females. Surgical treatment was carried out in $29 \%$ of all peptic ulcer patients.

We should like to thank Dr. J. G. McWhirter for his help in providing radiological details of these patients. We are grateful to the physicians and surgeons of the Infirmary who gave access to their records. We are indebted to Dr. J. Laurie and Mr. R. B. Wright for helpful criticism of the text.

\section{REFERENCES}

Alsted, G. (1953). Peptic ulcer in Denmark. Lancet, 2, 444.

Census (Scotland) 1951 (1956). Published Tables. H.M. Stationery Office, Edinburgh.

Doll, R., and Jones, F. A. (1951). Occupational factors in the aetiology of gastric and duodenal ulcers. Spec. Rep. Ser. med. Res. Coun. (Lond.), No. 276.
Dogra, J. R. (1940). Studies on peptic ulcer in south India. I. Introduction and clinical study of 258 cases. Indian J. med. Res., 28, $145-161$.

- (1941). Studies on peptic ulcer in south India. IV. Incidence of peptic ulcer in India with particular reference to south India. Ibid., 29, 665-676.

Finer, D. I., and Fry, J. (1955). Peptic ulcer in general practice. Brit. med. J., 2, 169-172.

Illingworth, C. F. W., Scott, L. D. W., and Jamieson, R. A. (1944), Acute perforated peptic ulcer, frequency and incidence in the West of Scotland. Ibid., 2, 617-620, 655-658.

Jamieson, R. A. (1955). Acute perforated peptic ulcer. Frequency and incidence in the West of Scotland. Ibid., 2, 222-227.

Jones, F. A., and Doll, R. (1953). Treatment and prognosis of acute perforated peptic ulcer. Ibid., 1, 122-127.

Konstam, P. G. (1954). Peptic ulceration in Southern Nigeria. Lancet, 2, $1039-1040$.

Leading Article (1960). Peptic ulcer in town and country. Lancet, 1, 476-477.

Lipetz, S. (1955). Gastro-intestinal ulceration and non-ulcerative dyspepsia in an urban general practice. Brit. med. J., 2, 172-177.

Mangold, R. (1958). Combined gastric and duodenal ulceration: a survey of 157 cases. Ibid., 2, 1193-1197.

Morris, J. N., and Titmuss, R. M. (1944). Epidemiology of peptic ulcer: vital statistics. Ibid., 2, 841-845.

Pulvertaft, C. N. (1959). Peptic ulcer in town and country. Brit. J. prev. soc. Med., 13, 131-138.

Watkinson, G. (1960). The incidence of chronic peptic ulcer found at necropsy. Gut, 1, $1,14$.

Weir, R. D. (1960). Perforated peptic ulcer in north-east Scotland. Scot. med. J., 5, 257-264. 